\title{
Size-fractioned ultrafine particles and black carbon associated with autonomic dysfunction in subjects with diabetes or impaired glucose tolerance in Shanghai, China
}

Yitong Sun ${ }^{1 \dagger}$, Xiaoming Song ${ }^{1 \dagger}$, Yiqun Han ${ }^{2}$, Yunfang $\mathrm{Ji}^{3}$, Shuna Gao ${ }^{3}$, Yu Shang ${ }^{4}$, Shou-en Lu ${ }^{5}$, Tong Zhu ${ }^{2}$ and Wei Huang ${ }^{1 *}$

\begin{abstract}
Background: Particles in smaller size fractions, such as ultrafine particles (UFPs) (with diameter less than $100 \mathrm{~nm}$ ), has become of significant cardiovascular health concerns. However, the biological plausibility underlying potential relationship between UFPs and cardiovascular outcomes is less studied.

Methods: Fifty-three subjects living in Shanghai with type-2 diabetes (T2D) or impaired glucose tolerance (IGT) were followed for autonomic dysfunctions with three repeated measurements in 2010. Minute-to-minute concentrations of ambient particles in small size-fractions $(5-560 \mathrm{~nm})$, black carbon $(\mathrm{BC})$, sulfur dioxide $\left(\mathrm{SO}_{2}\right)$, nitrogen dioxide $\left(\mathrm{NO}_{2}\right)$, carbon monoxide $(\mathrm{CO})$, and ozone $\left(\mathrm{O}_{3}\right)$ were monitored using a central monitoring laboratory equipped with real-time air monitors close to residential area of the subjects. Generalized linear mixed models, with adjustment for individual risk factors, were applied to assess the effects of air pollution on autonomic dysfunctions in subjects.

Results: Our study showed that significant reduction in the standard deviation of all NN intervals (SDNN) ranging from $3.4 \%$ to $8.1 \%$ were associated with interquartile range (IQR) increase of number concentration of particles (PNC) in size fractions $<100 \mathrm{~nm}$, and reduction from $1.3 \%$ to $4.6 \%$ with particles of diameter 100-200 nm, in subjects with diabetes or glucose tolerance. Increased exposure to traffic-related pollutants $\mathrm{BC}, \mathrm{NO}_{2}$ and $\mathrm{CO}$, and combustion pollutant $\mathrm{SO}_{2}$, were also significantly associated with $\mathrm{HRV}$ reductions. However, no effect was observed for particles in size fraction of 200-560 $\mathrm{nm}$ and $\mathrm{O}_{3}$. Diabetic risk factor and gender appeared to have significant interactions on autonomic dysfunction associated with UFPs and traffic pollution exposures in certain time-window.
\end{abstract}

Conclusions: Our results suggest that underlying diabetes or impaired glucose tolerance may confer reduced autonomic function of heart due to traffic pollution exposure.

Keywords: Ultrafine particulates, Black carbon, Traffic pollution, Heart rate variability, Diabetes, Impaired glucose tolerance

\footnotetext{
*Correspondence: whuang@bjmu.edu.cn

${ }^{\dagger}$ Equal contributors

1 Department of Occupational \& Environmental Health Sciences, and Institute

of Environmental Medicine, Peking University School of Public Health, and Key

Laboratory of Molecular Cardiovascular Sciences, Ministry of Education,

100191 Beijing, China

Full list of author information is available at the end of the article
} 


\section{Background}

Association between particulate matter, with diameter less than 10 and $2.5 \mu \mathrm{m}\left(\mathrm{PM}_{10}\right.$ and $\left.\mathrm{PM}_{2.5}\right)$, and cardiovascular diseases (CVD) has been supported by numerous epidemiologic studies [1]. Particles in smaller size fractions, such as ultrafine particles (UFPs) (with diameter less than $100 \mathrm{~nm}$ ), have have been reported that may contribute to increasing cardiovascular morbidity [2-4]. Particles emitted from transportation and industry combustion have been found dominating the number and surface concentrations of ambient particulate matters in small size fractions [4-6], and carrying large amount of adsorbed or condensed toxic air pollutants (oxidant gases, organic compounds, and transition metals) [7]. Studies reported that UFPs can potentially lead to acute cardiovascular responses [8-11]. However, compared to ambient $\mathrm{PM}_{2.5}$ and $\mathrm{PM}_{10}$, underlying biological plausibility of relationship between UFPs and cardiovascular morbidity has been far less studied.

Epidemiologic study findings suggested altered heart rate variability (HRV) as a possible mechanism linking ambient PM exposure to coronary heart disease events in subjects with preexisting cardiometabolic diseases [12-16]. Reduced HRV has been found associated with increasing risk of first cardiovascular event in population without known cardiovascular diseases [17], and associated with the development of coronary heart disease in individuals with diabetes [18]. The reduction of HRV derived from electrocardiographic (ECG) monitor recordings were found inversely associated with exposure to ambient PM originated from traffic and combustion sources $[19,20]$. Recent studies also reported the associations between HRV reduction and exposure to particles in smaller size including UFPs and particles in accumulation mode (with diameter less than $1 \mu \mathrm{m}$ ) [21,22], and among persons with cardiometabolic diseases or with metabolic syndromes [12,13,23,24]. However, the susceptibility of persons with cardiometabolic disease to the adverse effects of particulate matter is still uncertain, despite being biologically plausible.

Because of the increasing prevalence of diabetes and its association with an increasing risk of CVD, it is important to determine whether diabetes or impaired glucose tolerance may modify PM-HRV association. Some evidence suggests that ambient particles in small size fractions may play an important role in previously reported associations between traffic exposure and acute cardiovascular effects $[4,25,26]$. In this study, we assessed the role of exposure to particles in small size fractions 5-560 nm and black carbon (as a proxy for traffic related pollutant exposure) as cardiovascular risk factors in a group of subjects with diabetes or impaired glucose tolerance. We further examined if the association would be modified by diabetic state, obesity and gender.

\section{Results and discussion \\ Results}

The demographic and clinical characteristics of our study subjects are summarized in Table 1 . The age of subjects ranged from 51 to 68 years old. There was no significant difference in gender ratio between type-2 diabetes (T2D) and impaired glucose tolerance (IGT) groups, or between obese and non-obese groups $(p>0.1)$. No subject had severe cardiovascular diseases, except $68 \%$ of the subjects were with mild hypertension. All subjects with T2D were on regular medications (i.e. biguanides or sulfonylureas), and/or with insulin treatment; however, the subjects with IGT did not take regular medication, except one subject was taking biguanides regularly controlling for blood glucose level.

Summary statistics of particle number concentrations (PNC) in six aggregated size fractions, BC, gaseous pollutants, and meteorologic parameters are summarized in Table 2. Within all the size fractions of particles, which are those of diameters from $5 \mathrm{~nm}$ to $560 \mathrm{~nm}$, particles of size less than $200 \mathrm{~nm}$ dominated the number concentration, and ones of size 50-560 nm contributed the most of the surface concentration and the mass concentration (see Additional file 1).

All metrics of concentrations of particles in the size fraction $50-100 \mathrm{~nm}$ and $100-200 \mathrm{~nm}$ were highly correlated with $\mathrm{BC}, \mathrm{NO}_{2}$, and $\mathrm{CO}$ with correlation coefficients ranging from 0.55 to 0.78 (Table 3 and Additional file 1). The total number and surface area concentrations of particles were also highly correlated with $\mathrm{BC}$ and $\mathrm{NO}_{2}$. Particles in all size fractions of measurement were inversely correlated with $\mathrm{O}_{3}$, temperature and relative humidity $(\mathrm{RH})$.

\section{Table 1 Demographic characteristics for IGT and T2D} subjects

\begin{tabular}{lll}
\hline & IGT & T2D \\
\hline Number & 17 & 36 \\
Age (year) & $60.1(1.0)$ & $59.7(0.6)$ \\
BMI (kg/m²) & $25.3(0.7)$ & $26.7(0.7)$ \\
Gender (Female/Male) & $10 / 7$ & $17 / 19$ \\
Weight (kg) & $69.0(1.8)$ & $73.4(2.0)$ \\
Height (cm) & $165.2(1.4)$ & $165.4(1.1)$ \\
Waist (cm) & $92.2(2.7)$ & $92.8(1.7)$ \\
Hip circumference (cm) & $101.0(2.0)$ & $100.6(1.3)$ \\
Waist/hip circumference & $0.91(0.01)$ & $0.92(0.01)$ \\
SDNN (ms) & $119.6(7.5)$ & $108.6(4.4)$ \\
rMSSD (ms) & $23.8(3.2)$ & $19.8(0.9)$ \\
LF (ms $\left.{ }^{2}\right)$ & $305.2(62.5)$ & $263.7(25.5)$ \\
HF (ms ${ }^{2}$ ) & $160.7(62.0)$ & $95.9(10.2)$ \\
Hypertension & 8 & 28 \\
\hline
\end{tabular}


Table 2 Summary statistics of exposure and meteorologic parameters

\begin{tabular}{ll}
\hline & Mean (SD) \\
\hline $\mathrm{PNC}_{5-560}\left(1 / \mathrm{cm}^{3}\right)$ & $20220(11489)$ \\
$\mathrm{PNC}_{5-10}\left(1 / \mathrm{cm}^{3}\right)$ & $1378(1688)$ \\
$\mathrm{PNC}_{10-20}\left(1 / \mathrm{cm}^{3}\right)$ & $4032(4087)$ \\
$\mathrm{PNC}_{20-50}\left(1 / \mathrm{cm}^{3}\right)$ & $6276(4603)$ \\
$\mathrm{PNC}_{50-100}\left(1 / \mathrm{cm}^{3}\right)$ & $5074(2858)$ \\
$\mathrm{PNC}_{100-200}\left(1 / \mathrm{cm}^{3}\right)$ & $2544(1675)$ \\
$\mathrm{PNC}_{200-560}\left(1 / \mathrm{cm}^{3}\right)$ & $272(238)$ \\
$\mathrm{BC}\left(\mu \mathrm{g} / \mathrm{m}^{3}\right)$ & $4.09(2.37)$ \\
$\mathrm{NO}_{2}(\mathrm{ppb})$ & $32.52(16.89)$ \\
$\mathrm{CO}(\mathrm{ppm})$ & $0.61(0.33)$ \\
$\mathrm{SO}_{2}(\mathrm{ppb})$ & $6.53(5.28)$ \\
$\mathrm{O}_{3}(\mathrm{ppb})$ & $25.83(18.7)$ \\
Temperature $\left({ }^{\circ} \mathrm{C}\right)$ & $22.62(6.18)$ \\
$\mathrm{RH}(\%)$ & $67.86(12.54)$ \\
Air pressure $(\mathrm{bar})$ & $1013.96(6.42)$ \\
\hline
\end{tabular}

SD for standard deviation and IQR for interquatile range. The observations of all the pollutants and meteorologic parameters were obtained in 1 minute interval covering the whole period of each visit in April, June and September.

In Figure 1, we presented the adjusted percent changes of standard deviation of all NN intervals (SDNN) per interquartile range (IQR) increase of number concentrations of particles in all size fractions, $\mathrm{BC}$, and gaseous pollutants in various time windows of pollutant exposure, controlling age, gender, body mass index (BMI), time of day, day of week, temperature, $\mathrm{RH}$ and visit. Greater reductions in SDNN were associated with increase in exposure to particles in smaller size fractions $<100 \mathrm{~nm}$, followed by particles in 100-200 $\mathrm{nm}$. Increased exposure to traffic-related pollutants $\mathrm{BC}, \mathrm{NO}_{2}$ and $\mathrm{CO}$, and combustion pollutant $\mathrm{SO}_{2}$, were also significantly associated with SDNN reductions. Overall, the inverse associations were the strongest for 4-hour average air pollutants exposure. No effect was observed for particles in size fraction of 200-560 nm and $\mathrm{O}_{3}$. Similar association patterns are observed for other HRV measures, including the root mean square of successive differences between adjacent normal cycles (rMSSD), low frequency (LF) $(0.04-0.15 \mathrm{~Hz})$ and high frequency (HF) $(0.15-0.4 \mathrm{~Hz})$, whereas the magnitude of reduction for frequency-domain measure LF and HF were greater (see Additional file 2).

To control the confounding effects of highly correlated pollutants, we compared the estimated effects of prior 4-hour average exposure to all size-fractioned particles, $\mathrm{BC}, \mathrm{O}_{3}$, and $\mathrm{NO}_{2}$ in single- and two-pollutant models (Table 4). In two-pollutant models with adjustment for $\mathrm{BC}$, the magnitude of effect estimates remained similar for number concentrations of particles of size 10 to $20 \mathrm{~nm}\left(\mathrm{PNC}_{10-20}\right), \mathrm{NO}_{2}$, and $\mathrm{CO}$ as the magnitude in single-pollutant models. The magnitude of effects was reduced for $\mathrm{PNC}_{20-50}, \mathrm{PNC}_{50-100}$ and $\mathrm{PNC}_{5-560}$, whereas the effects became insignificant for $\mathrm{PNC}_{100-200}$ and $\mathrm{PNC}_{200-560}$. With adjustment for $\mathrm{BC}$, the associations with surface area concentrations of particles (PSC), and mass concentrations of particles (PMC), remained significant for particles in size-fraction 10-20 nm and 20$50 \mathrm{~nm}$ only. In two-pollutant models with adjustment for $\mathrm{NO}_{2}$, the associations between SDNN and all measured pollutants, except $\mathrm{BC}$, remained robust and consistent as assessed in single-pollutant models. We did not observe confounding effects of exposure to $\mathrm{O}_{3}$ (results summarized in Additional file 3).

Between subjects with T2D and in prediabetic state with IGT, effects assessed at 4- and 24-hour average exposure were presented in Figures 2 and 3. For prior 4-hour average air pollution exposure, we did not observe significant heterogeneity in effect estimates (with $p$ values for interaction $>0.05$ ); however, effects in subjects with IGT were significantly stronger with prior 24-hour average exposure (with $p$ values for interaction $<0.05$ ).

Figure 4 shows the interaction effect of obesity on associations between SDNN and 4-hour average of air pollution exposure. Subjects with BMI $>25 \mathrm{~kg} / \mathrm{m}^{2}$ were found of greater SDNN reduction associated with exposure to air pollution, and the risk was even higher in subjects with $\mathrm{BMI}>28 \mathrm{~kg} / \mathrm{m}^{2}$ (with $p$ values for interaction $<0.05$ ). However, we did not find significant interaction of central

Table 3 Correlations between number concentration of particles in each size fraction, and BC, gaseous pollutants and meteorologic parameters

\begin{tabular}{lllllllll}
\hline & $\mathbf{B C}$ & $\mathbf{N O}_{2}$ & $\mathbf{C O}$ & $\mathbf{S O}_{\mathbf{2}}$ & $\mathbf{O}_{\mathbf{3}}$ & $\mathbf{T}$ & RH & Air pressure \\
\hline PNC $_{5-560}$ & 0.52 & $0.65^{*}$ & 0.45 & 0.48 & -0.1 & -0.13 & -0.14 & 0.18 \\
PNC $_{5-10}$ & -0.06 & 0.16 & -0.05 & 0.09 & 0.08 & -0.2 & -0.15 & 0.34 \\
PNC $_{10-20}$ & 0.13 & 0.35 & 0.08 & 0.1 & 0.02 & -0.08 & -0.19 & 0.25 \\
PNC $_{20-50}$ & 0.35 & 0.54 & 0.36 & 0.38 & -0.14 & -0.04 & -0.14 & 0.21 \\
PNC $_{50-100}$ & $0.75^{*}$ & $0.78^{*}$ & $0.65^{*}$ & 0.58 & -0.28 & -0.12 & -0.07 & 0.04 \\
PNC $_{100-200}$ & $0.72^{*}$ & $0.7^{*}$ & 0.56 & $0.6^{*}$ & -0.07 & -0.2 & -0.09 & 0.15 \\
PNC $_{200-560}$ & 0.37 & 0.36 & 0.3 & 0.31 & -0.05 & -0.19 & 0 & 0.18 \\
\hline
\end{tabular}

T for temperature and * indicates correlation coefficients $>0.6$. 


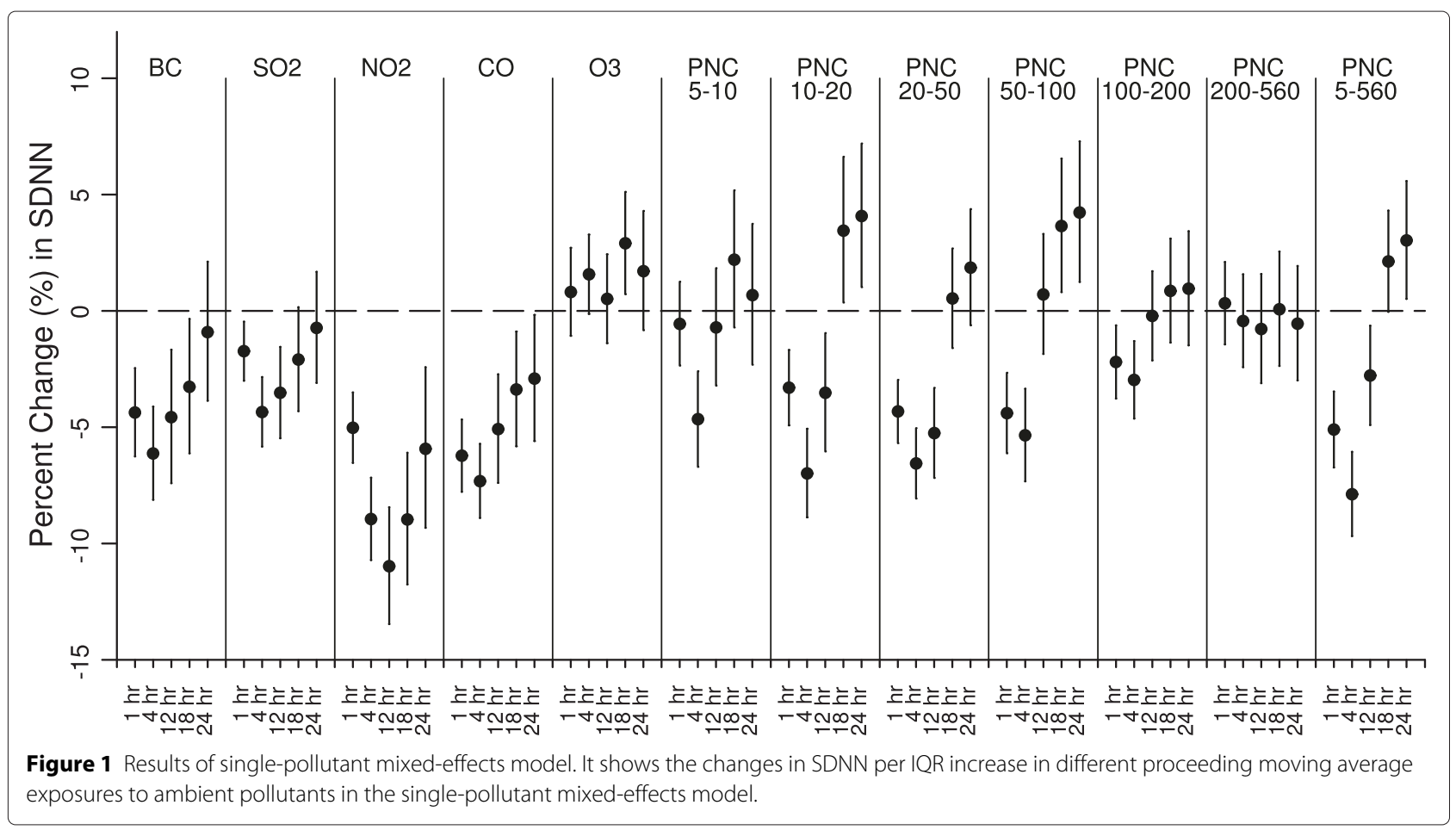

adiposity in female nor in male subjects, though subjects with lower waist to hip ratio appeared in greater SDNN reduction associated with exposure to air pollution (with $p$ values for interaction $>0.05$, data in Additional file 4). The correlation coefficients between obesity index BMI and central adiposity index waist to hip ratio (WHr) ranged 0.27 to 0.45 in our subjects.

In the regression analyses of 4-hour average exposure stratified by gender, with controlling for same covariates in main models, we observed significant heterogeneity of gender (with $p$ values for interaction $<0.05$ ) (Figure 5). Per IQR increase in 4-hour average of $\mathrm{PNC}_{5-560}\left(10,300 \mathrm{~cm}^{3}\right)$, we observed $-12.0 \%$ (95\% CI, $-14.1 \%$ to $-9.8 \%)$ in SDNN in female, and $-4.2 \%(95 \% \mathrm{CI},-6.4 \%$ to $-1.9 \%)$ in male, with $p$ value for interactions $<0.05$. The modifiction effect of gender were significant when exposure to particles in size fraction $<200 \mathrm{~nm}, \mathrm{NO}_{2}, \mathrm{SO}_{2}$, or $\mathrm{CO}$ was considered, and marginally significant on $\mathrm{BC}$ exposure.

\section{Discussion}

In our study, we observed significant inverse associations between autonomic dysfunctions in subjects with diabetes

Table 4 Percent change in SDNN per IQR increases in proceeding 4-hour moving average exposures to ambient pollutants estimated in single-, and two-pollutant mixed-effects models

\begin{tabular}{|c|c|c|c|c|c|}
\hline & \multirow[t]{2}{*}{ Single-pollutant } & \multicolumn{4}{|c|}{ Two-pollutant } \\
\hline & & Adj. for BC & Adj. for $\mathrm{NO}_{2}$ & Adj. for $\mathrm{O}_{3}$ & Adj. for CO \\
\hline$B C$ & $-6.14(-8.12,-4.11)$ & $-6.14(-8.12,-4.12)$ & $1.09(-1.72,3.98)$ & $-5.18(-7.31,-3)$ & $0.07(-2.7,2.91)$ \\
\hline $\mathrm{NO}_{2}$ & $-8.98(-10.72,-7.18)$ & $-9.56(-11.85,-7.2)$ & $-8.97(-10.72,-7.18)$ & $-9.33(-11.34,-7.27)$ & $-6.43(-8.64,-4.17)$ \\
\hline $\mathrm{CO}$ & $-7.33(-8.91,-5.73)$ & $-7.37(-9.43,-5.25)$ & $-7.05(-8.95,-5.11)$ & $-6.68(-8.52,-4.81)$ & $-4.22(-6.19,-2.21)$ \\
\hline $\mathrm{SO}_{2}$ & $-4.36(-5.85,-2.86)$ & $-2.91(-4.66,-1.13)$ & $-0.56(-2.38,1.30)$ & $-3.24(-4.83,-1.62)$ & $-1.25(-3.02,0.55)$ \\
\hline $\mathrm{O}_{3}$ & $1.55(-0.13,3.27)$ & $0.51(-1.22,2.27)$ & $1.55(-0.14,3.28)$ & $0.94(-0.77,2.68)$ & $-1.73(-3.51,0.09)$ \\
\hline $\mathrm{PNC}_{5-560}$ & $-7.89(-9.69,-6.07)$ & $-6.82(-8.87,-4.72)$ & $-7.73(-9.57,-5.85)$ & $-7.47(-9.65,-5.24)$ & $-4.54(-6.82,-2.21)$ \\
\hline $\mathrm{PNC}_{10-20}$ & $-7.0(-8.88,-5.08)$ & $-7.05(-8.92,-5.14)$ & $-7.21(-9.14,-5.24)$ & $-6.73(-8.65,-4.77)$ & $-6.18(-8.1,-4.21)$ \\
\hline $\mathrm{PNC}_{20-50}$ & $-6.57(-8.07,-5.04)$ & $-5.77(-7.34,-4.17)$ & $-6.36(-7.92,-4.77)$ & $-6.07(-7.77,-4.33)$ & $-4.32(-6.07,-2.53)$ \\
\hline $\mathrm{PNC}_{50-100}$ & $-5.37(-7.34,-3.35)$ & $-2.76(-5.29,-0.16)$ & $-5.65(-7.69,-3.56)$ & $-3.49(-6.03,-0.89)$ & $1.52(-1.32,4.45)$ \\
\hline $\mathrm{PNC}_{100-200}$ & $-2.98(-4.63,-1.3)$ & $2.53(-0.29,5.42)$ & $-2.53(-4.26,-0.77)$ & $0.3(-1.84,2.49)$ & $2.83(0.71,4.99)$ \\
\hline $\mathrm{PNC}_{200-560}$ & $-0.45(-2.43,1.56)$ & $5.15(2.53,7.84)$ & $0.09(-1.96,2.18)$ & $3.25(0.97,5.59)$ & $4.46(2.22,6.75)$ \\
\hline
\end{tabular}




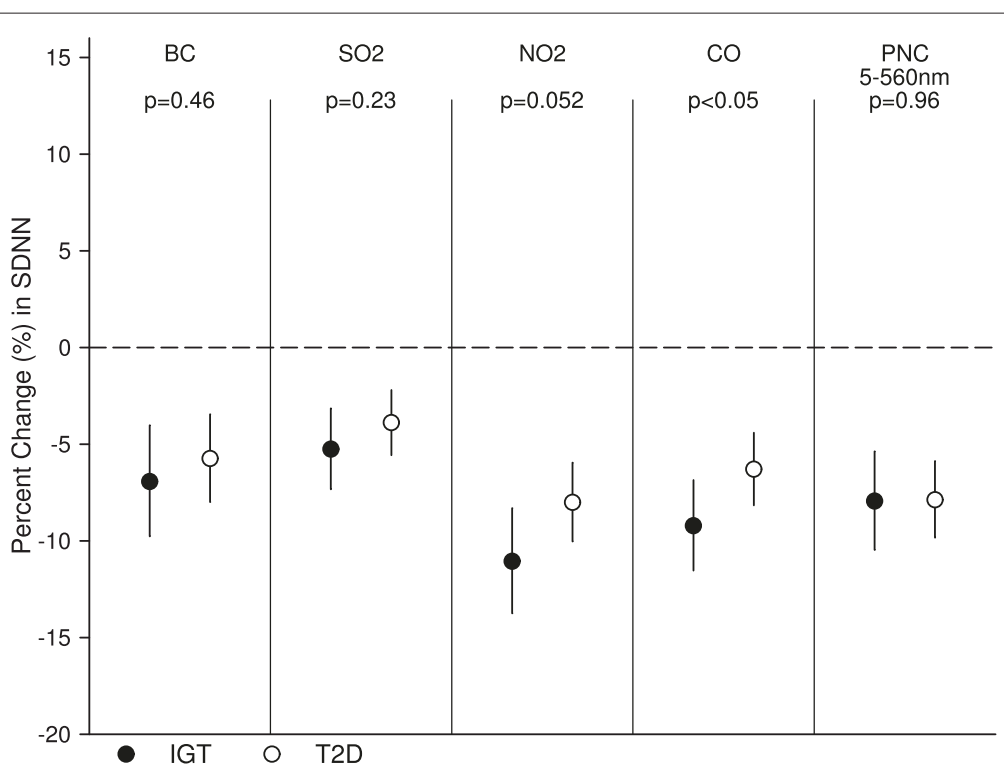

Figure 2 Stratified analysis by diabetic states. It shows estimates for adjusted percent changes in SDNN per IQR increase in 4-hour average exposures to different air pollutants in IGT and T2D groups.

and impaired glucose tolerance and exposure to ambient particles in small size fractions (diameter less than $200 \mathrm{~nm}$ ), $\mathrm{BC}, \mathrm{NO}_{2}$ (traffic pollution proxy) and $\mathrm{CO}$. The associations were stronger in subjects with obesity and in female. However, the interaction effect of diabetic states was not consistent over different averaging hours. Our findings suggest that possible cardiovascular effects associated with traffic pollution exposure may be mediated, in part, through altered autonomic function, among persons with diabetes or impaired glucose tolerance. Our findings have broad clinical and public health implications for air pollution induced cardiometabolic risks.

UFPs are an important component of combustionrelated or secondary aerosol-related air pollution with large amount of toxic air pollutants and chemicals adsorbed on its surfaces. With its high lung deposition efficiency in the lungs, UFPs can enter into pulmonary interstitial sites and through circulation system

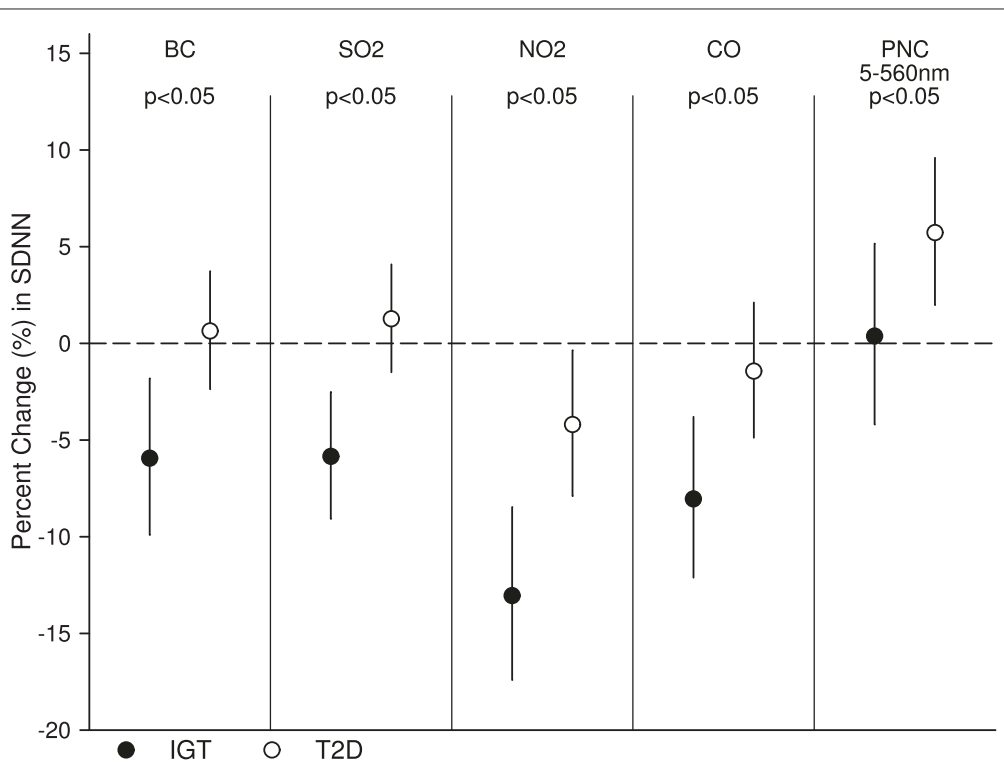

Figure 3 Stratified analysis by diabetic states. It shows estimates for adjusted percent changes in SDNN per IQR increase in 24-hour average exposures to different air pollutants in IGT and T2D groups. 


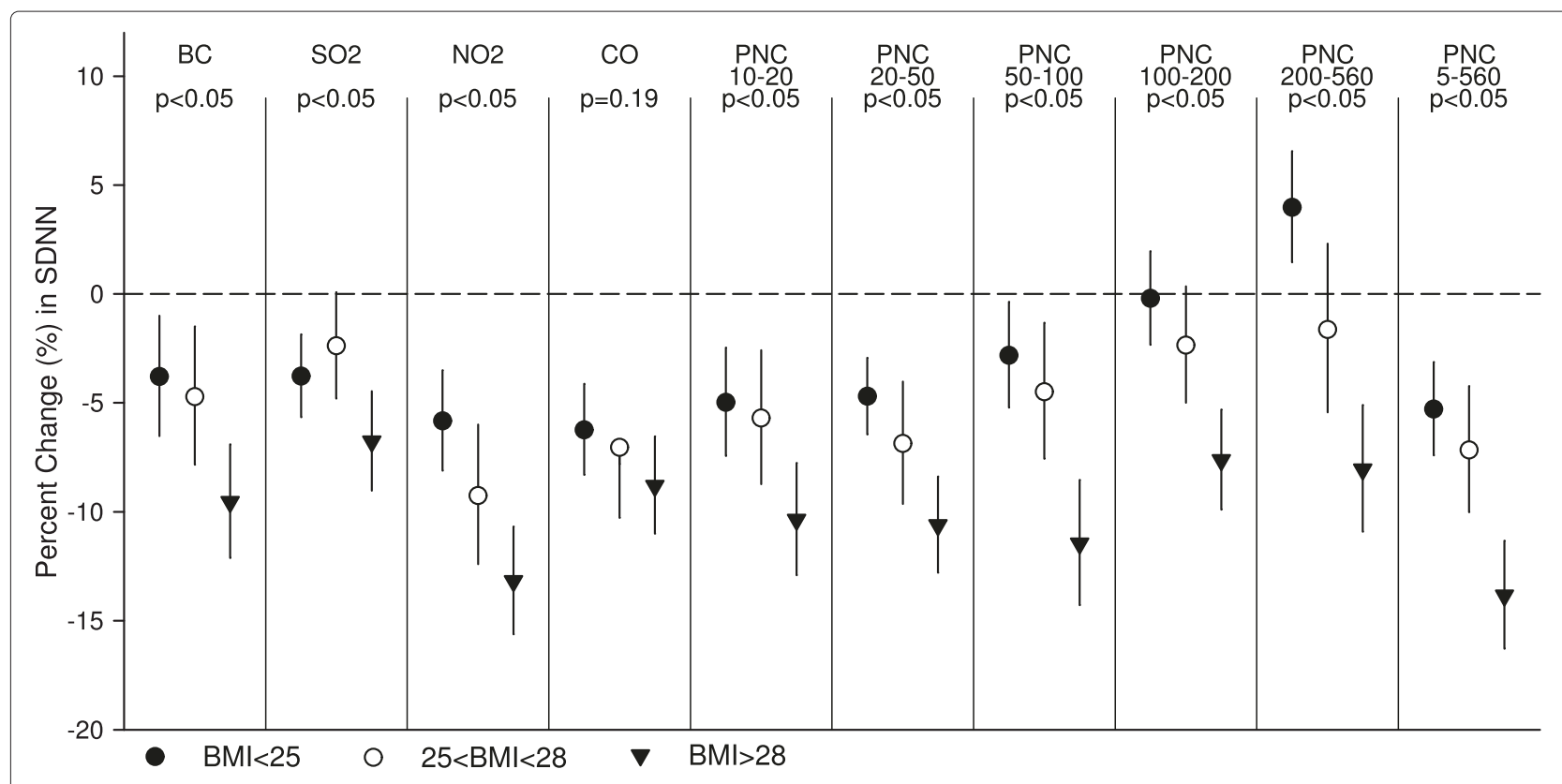

Figure 4 Stratified analysis by obesity. It shows estimates for adjusted percent changes in SDNN per IQR increase in 4-hour average exposures to different air pollutants in three groups stratified based on BMI.

reaching other target sites. The hypothesized intermediary pathophysiologic pathways associated with UFP exposures include release of proinflammatory mediators or vasculoactive molecules from lung-based cells, perturbation of systemic autonomic nerve system balance or heart rhythm, and potentially translocation of PM or PM constituents into circulation system [27]. Thus, we focused on examining cardiovascular risk associated with exposure to particles in small size fractions (between 5 to $560 \mathrm{~nm}$ ) including UFPs, and traffic pollution markers $\left(\mathrm{BC}, \mathrm{NO}_{2}\right.$, and $\left.\mathrm{CO}\right)$. Our overall results support the hypothesis that greater cardiovascular responses are associated with UFPs than with larger particles, and are consistent with findings of autonomic, vascular and

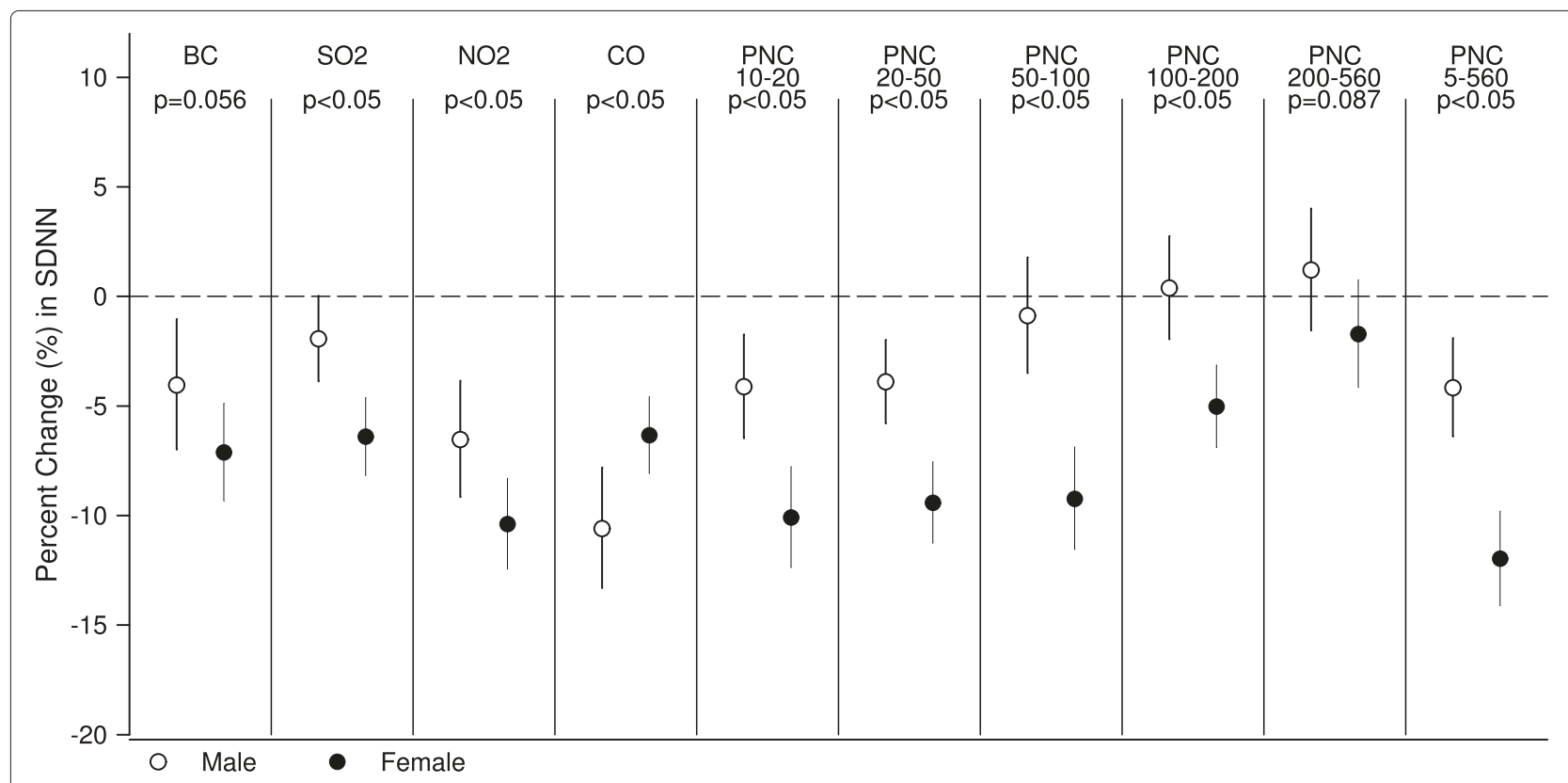

Figure 5 Stratified analysis by gender. It shows estimates for adjusted percent changes in SDNN per IQR increase in 4-hour average exposures to different air pollutants in male and female groups. 
thrombotic effects of UFPs inhalation observed in susceptible and healthy subjects $[21,22,25,28,29]$.

However, the associations between UFPs exposures and acute changes in HRV reported in previous studies are not consistent and the directions and magnitudes of the associations varied across study locations. Chan et al. reported significant inverse relationship between hours prior average UFP exposures in HRV in a panel of healthy and elderly patients, with stronger effects in elderly subjects in Taiwan [30]. Weichenthal et al. reported significant reduction in HF and the proportion of NN50 divided by total number of NNs (pNN50) within hours immediately following UFP exposures in healthy cyclists in traffic in Ottawa, Canada [21].

Park et al. observed inverse association between ambient UFP exposures over 48-hour moving averages and HRV in elderly male subjects in Boston, USA, though the associations were not statistically significant [23].

In more recent studies, Schneider et al. did not observe significant associations between fixed-site ambient UFP measures and HRV over up to 47 lag hours in elderly men with coronary artery disease in Erfurt, Germany [14]; whereas Rich et al. reported decreased rMSSD associated with UFP exposures at significant level, but not with particles in accumulation mode $(100-500 \mathrm{~nm})$ and $\mathrm{PM}_{2.5}$, in a cardiac panel in rehabilitation in Rochester, USA [22]. Vora et al. lately reported that inhalation of elemental carbon ultrafine particles can alter heart rate and HRV in subjects with T2D [31]. It is possible that other pathophysiological factors such as activation of the renin-angiotensin system, oxidative stress, and inflammatory status in subjects with cardiovascular morbidities may have modulated the association between air pollution exposure and autonomic nervous system dysfunction.

Pathophysiologically, autonomic nervous system dysfunction also relates to insulin resistance [32,33], and abnormal glucose metabolism $[34,35]$. Park et al. reported significant HRV reduction in subjects with metabolic syndrome associated with exposure to 2-day average $\mathrm{PM}_{2.5}$ in six US communities in the Multi-Ethnic Study of Atherosclerosis (MESA) study, whereas no significant change was found among subjects without metabolic syndrome [13]. Whitsel et al. observed stronger inverse $\mathrm{PM}_{10}$-HRV associations in subjects with diabetes, and diabetic subjects of higher insulin and insulin resistance level were of statistically greater HRV reduction [12]. Recently, Min et al. observed a significant reduction in HRV related to exposure to carbon monoxide $(\mathrm{CO})$ among persons with metabolic syndrome but not among persons without metabolic syndrome [36]. In our analysis, we examined the roles of diabetic state in modifying autonomic dysfunctions associated with ambient pollution. We observed significantly stronger inverse associations with 24-hour prior exposure to UFPs and traffic pollutants in subjects with IGT who did not receive regular medication to control for glucose level, but not in T2D subjects. However, with 4-hour prior exposure, the interaction of diabetic state between subjects with T2D and with IGT was not significant. The differential responses observed may be partially explained by insulin resistance or glucose metabolism altered by medication use in subjects.

As an important risk factors of metabolic syndrome, obesity is closely correlated with increased systemic inflammation and oxidative stress that are cardiovascular risk factors $[37,38]$. There is a growing body of evidence that $\mathrm{T} 2 \mathrm{D}$ is a chronic inflammatory state aggravated by factors that promote inflammation at the level of vasculature and adipose tissue [39,40], and increased oxidative stress to adipocytes is central to the pathogenesis of cardiovascular disease in metabolic syndrome [41]. Air pollution may also promote T2D by increasing adipose inflammation and insulin resistance. Sun et al. recently found that $\mathrm{PM}_{2.5}$ exposure exaggerates whole-body insulin resistance and adiposity inflammation in mice [42]. Consistent with previous studies $[20,24]$, obesity modified air pollution attributed cardiac autonomic function in our subjects. However, we did not observe interaction of abdominal fat accumulation. It seems plausible to hypothesize that adipose tissues located at different sites of body may have different metabolic properties in predisposing reduced skeletal muscle glucose utilization and insulin resistance, thus to pose differential mechanisms in regulation and/or impairments in sympathetic nervous system function associated with air pollution exposure.

Previous research suggested that gender could modify the cardiovascular risk and air pollution associations; however, the findings are heterogeneous $[43,44]$. Recent studies reported higher traffic pollution associated with cardiometabolic risks in females. Brook et al. found an association between modeled $\mathrm{NO}_{2}$ exposure and T2D prevalence among female patients, but not among male patients, of two respiratory health clinics in Canada [45]. A study by Kramer et al. supported the plausibility of oxidative stress and inflammation as a biological mechanism for the relation between air pollution and T2D, by showing that females with high C3c blood levels (a marker for subclinical inflammation) were more susceptible for particulate matter related excess risk of diabetes than were females with low C3c levels. This prospective study furthermore found a relation between traffic-related particulate matter and incident T2D among elderly women in Germany [46]. In addition, an American study found an association with distance to road among women, while no strong evidence of an association with particulate matter exposure was observed [47]. Consistent with our previous analysis [20], we observed greater HRV declines associated with exposures to traffic-related pollutants BC and gaseous pollutants in female elderly Chinese. Yet the 
prevalence of obesity and distribution of adipose tissue differ by age and gender which could modify cardiac responses pathophysiologically, the mechanisms for age, obesity and gender specific interactions of air pollution associated cardiovascular effects are not yet clear and deserve further investigation.

Several study limitations should also be noted in interpreting our findings. First, we only investigated subjects with T2D and IGT, and had no normal glucose tolerant or lean control subjects. Second, we did not collect individual data, such as insulin level and insulin resistance, homeostasis, systemic inflammation and oxidative stress, which might have limited our capability further examining the biological plausibility of diabetes in modifying UFPs and traffic pollution associated cardiovascular dysfunctions. Third, the fixed-location monitoring data was used in this study, and the lack of information on personal exposure to ambient pollution may have resulted in potential exposure misclassification errors and may have biased the effect estimates toward null. Fourth, we did not control subjects' activity during observation, which may affect the results of frequency-domain measurement of HRV. And lastly, we did not obtain real-time minute-to-minute $\mathrm{PM}_{2.5}$ concentrations due to operational errors of the monitoring instruments installed in the monitoring laboratory. Thus we were not able to examine the commonly studied associations between autonomic dysfunction and exposure to criteria pollutant $\mathrm{PM}_{2.5}$, which has limited the generalization of our results in broader context of adverse effects of ambient fine particulates.

In summary, we observed autonomic dysfunction associated with increased exposure to ambient UFPs and traffic-related pollutants in previous hours among persons with diabetes or impaired glucose tolerance, and the magnitude of estimated effects were significantly stronger in obese persons and in females. Our results suggest that underlying metabolic condition may confer susceptibility of traffic pollution on the heart.

\section{Materials and methods}

\section{Study design and subjects}

This panel study was conducted in April, June and September of 2010. We recruited 53 elderly subjects with diagnosed type- 2 diabetes or impaired glucose tolerance through an existing diabetes cohort followed by Luwan District Center for Disease Control (CDC) and Prevention in Shanghai. The diabetes cohort was designed to allow randomized or controlled evaluation of behavior and dietary modification on progression and risk factors of T2D. Since 2004, this cohort has enrolled approximately 4,000 individuals with diagnosed T2D or at risk, but free of clinically apparent cardiovascular diseases at baseline examination. At the enrollment, the disease state of each individual was identified by standardized medical record review and physician adjudication. During the follow-up, fasting plasma samples were measured every six months.

All the subjects were retired elderly living within one kilometer from Luwan CDC in central Shanghai. The information on subjects' age, gender, weight, height, smoking status and medical history was obtained through administered baseline questionnaire interview during recruitment process. Our subjects received three repeated measurements of 24-hour ambulatory ECG during study period. The Institutional Review Board of Peking University Health Science Center approved study protocol and written consent form. Informed consent was obtained from each participant before the study participation.

\section{Individual metabolic abnormality measurement}

Our subjects had fasting blood samples drawn and measured for plasma glucose, gycosylated hemoglobin, triglyceride, and cholesterol in routine follow-up in April and October in 2010. Each participant was scheduled arriving the check-up room in Luwan CDC at the same time of a weekday morning for all visits. At each visit, technical staff measured body weight, height, waist and hip circumferences, and blood pressure of each subject, and recorded 24-hour activity of the subjects prior to the visit through questionnaire survey. We used clinical cutoff points for diabetic states: T2D was defined as fasting blood glucose $\geq 126 \mathrm{mg} / \mathrm{dL}$.

\section{HRV measures}

After physical examination at each visit, trained personnel placed 7 bipolar leads of a ECG monitor on the participant, following standard protocol. HRV were derived from 24-h ECG recordings of subjects, under normal daily activity conditions, using a 3-channel Holter monitoring system (Model MGY H7, DM Software Inc., USA).

The ECG digital recordings were reviewed and processed by trained cardiologists. Mean heart rate and various measure of HRV were calculated for each 24-Hour session using PC-based software (Holter System Version 12.Net for Windows, DM Software). Each 5-minute segment of normal to normal intervals of the heart beat was used to calculate the HRV index that included timedomain measurements of SDNN and rMSSD, as well as frequency-domain measurements of LF and HF.

\section{Air pollution measures}

Air pollution concentrations and meteorological data were monitored continuously using instruments equipped in a laboratory in Luwan CDC. The repeatability, accuracy, and predictive validity of the air pollution measurements conducted by the laboratory have been described previously [48].

Minute-to-minute number concentration of particles in size between 5 to $560 \mathrm{~nm}$ was monitored by a Fast 
Mobility Particle Sizer Spectrometer (FMPS Model 3091, Thermo, USA). Number-size distributions were converted to particle number concentrations, particle surface area concentrations, and particle mass concentrations, assuming spherical particles and $1 \mathrm{~g} / \mathrm{cm}^{3}$ as default density parameter. In this analyses, we calculated 5-minute mean concentration for particles in $5-10 \mathrm{~nm}, 10-20 \mathrm{~nm}$, 20-50 nm, 50-100 nm, $100-200 \mathrm{~nm}, 200-560 \mathrm{~nm}$ size fractions. Total number, surface, and area concentrations of particles were computed as the sum of all fractions (5-560 nm).

We also measured real-time concentrations of $\mathrm{BC}, \mathrm{SO}_{2}$, $\mathrm{NO}_{2}, \mathrm{CO}$, and $\mathrm{O}_{3}$. Minute-to-minute $\mathrm{BC}$ concentration was measured by Multi Angle Absorption Photometer (MAAP Model 5012, Thermo Fisher Scientific Inc., USA). Minute-to-minute $\mathrm{SO}_{2}, \mathrm{NO}_{2}, \mathrm{CO}$, and $\mathrm{O}_{3}$ concentrations were monitored by EC9800 Series Ambient Gas Analyzers (Eco Tech Pty. Ltd., Australia). Temperature $\left({ }^{\circ} \mathrm{C}\right)$ and relative humidity (\%) were measured by a Met One unit (Met One Instruments Inc., USA).

\section{Statistical analysis}

We calculated descriptive statistics for each air pollution measurement. Spearman correlations were calculated across minute-to-minute data of air pollutants and meteorologic parameters. All HRV variables were logarithmically transformed using base 10 due to right skewed distributions.

We first built basic generalized linear mixed models with each HRV metric as the dependent variable. Based on the assessment of Akaikes information Criterion (AIC), we chose to model the temperature and $\mathrm{RH}$ using natural splines with degree of freedom up to 3 , and modeled time of the day using quadratic polynomial functions. The first-order autoregressive model (AR1) was chosen to account for intra-subject correlation within each visit between repeated measures after comparison of several covariance structures, based on the criteria of minimizing AIC. The effect of uncontrolled features of subjects was modeled by random coefficient relying on subjects' id. Models were also adjusted for potential confounders such as day of week, age, gender, BMI and visit.

Single-pollutant models were then developed by including pollutant variables to examine the associations between air pollution exposure and HRV measures. The effects of particles in all size-fractions and other pollutants under 1-, 4-, 12-, 18-, and 24-hour moving averages were examined. Due to relatively high correlation between concentration of particles and other air pollutants, we conducted two-pollutant analyses by including the second pollutant of prior 4-hour average exposure to examine the robustness of the estimates associated with particles.

To evaluate potential effect modification by status of disease and other factors, we conducted the analysis of
SDNN with each air pollutant using the 4-hour averaging exposure, stratified by diabetic state (T2D vs. IGT), obesity (Group 1, BMI $\leq 25$; Group 2, $25 \leq \mathrm{BMI} \leq 28$; Group 3, $28 \leq \mathrm{BMI}$ ), central adiposity (WHr), and gender, controlling the same covariates as in main models. We examined the heterogeneity in the association estimates across strata at the .05 significance level.

All effect estimates were expressed as percent change in each HRV variable for interquartile range (IQR) increase of the corresponding moving average of each pollutant, calculated as $\left[10^{(\beta \times I Q R)}-1\right] \times 100$, with $95 \%$ confidence intervals $(C I)\left\{10^{[I Q R \times(\beta \mp 1.96 \times S E)]}-1\right\} \times 100$, where $\beta$ and $S E$ are the estimated regression coefficient and its standard error. All analyses were conducted in SAS statistical software (Version 9.2; SAS Institute; Cary, NC).

\section{Additional files}

Additional file 1: Description and correlations. This file contains 2 sheets. One is named 'description_of_pollutants', which is the extension of Table 2, with basic descriptive statistics of surface concentration (PSC) and mass concentration (PMC) of particles. The numbers after PSC or PMC indicate the size fraction of particles. Another sheet is named 'correlations_among_pollutants', which is an extension of Table 3, with correlations between surface or mass concentration of particles in each size fraction, and BC, gaseous pollutants and meteorologic parameters. $T$ for temperature and * indicates correlation coefficients $>0.6$.

Additional file 2: Per IQR change single pollutant. This file contains 26 sheets. The name of the sheet gives the pollutant whose effect is shown in it, and the numbers after PNC, PMC or PSC indicate the size fraction of particles. Each sheet shows the percent change of all $5 \mathrm{HRV}$ metrics, SDNN, rMSSD, LF, HF and LF/HF, in response to the IQR increases in 1-. 4-, 12-, 18-, and 24-hour moving averaged exposure to air pollutants. The column 'Yvar' indicates the HRV metric and the second column label the moving average. The column 'Per IQR $\uparrow$ ' shows the percent change of the HRV metric, and the columns '95\% Cl-Low' and '95\% Cl-High' give the lower and upper bounds of $95 \%$ confidence interval.

Additional file 3: Per IQR change two pollutant. This file contains 1 sheet. It shows the effects of different metrics of particles on SDNN when another gaseous pollutant or BC is also included in the model. The time window for all pollutants is 4 hours prior to the HRV observation. The column 'Confound Pol' indicates which pollutant is included in the model to detect confounding effect. The column 'Effect Pol' indicates which pollutant is potentially confounded. The numbers after PNC, PMC or PSC indicate the size fraction of particles. The column 'Per IQR $\uparrow$ ' shows the percent change of SDNN, and the columns '95\% Cl-Low' and '95\% Cl-High' give the lower and upper bounds of $95 \%$ confidence interval.

Additional file 4: Per IQR change stratified. This file contains 5 sheets. Each sheet shows the modification effect of a factor discussed in this study. The ratio of waist to hip circumference $(\mathrm{WHr})$ is analyzed within each gender due to different classification criteria. We only considered the effect on SDNN and pollutants under prior 4-hour moving average for gender, $\mathrm{BMI}$ and $\mathrm{WHr}$. For the modification effect of diabetic state, we analyzed both 4-hour and 24-hour time window. The group label is given in the first row of each sheet. The numbers after PNC, PMC or PSC indicate the size fraction of particles. The column 'Per IQR $\uparrow$ ' shows the percent change of SDNN within each group, and the columns '95\% Cl-Low' and '95\% Cl-High' give the lower and upper bounds of $95 \%$ confidence interval.

\section{Competing interests}

The authors declare that they have no competing interests. 


\section{Authors' contributions}

YTS, YQH, YFJ, SNG and YS collected sample and measurement data, YTS, XMS and $\mathrm{WH}$ analyzed the data and drafted the manuscript, SL supervised data analysis, WH and TZ designed and managed the study. All authors read and approved the final manuscript.

\section{Acknowledgements}

This study was supported by Ministry of Science and Technology of China (grant 2008AA062503), the Ministry of Environmental Protection of China (grant 201009032), and the National Science Foundation of China (grant 21190051). Dr Lu is partially supported by the US National Institute of Environmental Health and Safety (grant 2P30ES005022-21).

\section{Author details}

${ }^{1}$ Department of Occupational \& Environmental Health Sciences, and Institute of Environmental Medicine, Peking University School of Public Health, and Key Laboratory of Molecular Cardiovascular Sciences, Ministry of Education, 100191 Beijing, China. ${ }^{2}$ College of Environmental Sciences and Engineering, Peking University, Beijing, China. ${ }^{3}$ Center for Diseases Control and Prevention of Luwan District, Shanghai, China. ${ }^{4}$ Institute of Environmental Pollution and Health, Shanghai University, Shanghai, China. ${ }^{5}$ Department of Biostatistics, UMDNJ-School of Public Health, Piscataway, New Jersey, US

Received: 21 November 2014 Accepted: 23 February 2015 Published online: 25 March 2015

\section{References}

1. Brook RD, Rajagopalan S, Pope CA, Brook JR, Bhatnagar A, Diez-Roux $A V$, et al. Particulate matter air pollution and cardiovascular disease: An update to the scientific statement from the american heart association. Circulation. 2010;121(21):2331-78.

2. Utell MJ, Frampton MW. Acute health effects of ambient air pollution: the ultrafine particle hypothesis. J Aerosol Med: Official J Int Soc Aerosols Med. 2000;13(4):355-9.

3. Delfino RJ, Sioutas C, Malik S. Potential role of ultrafine particles in associations between airborne particle mass and cardiovascular health. Environ. Health Perspect. 2005;113(8):934-46.

4. Knol AB, de Hartog JJ, Boogaard H, Slottje P, van der Sluijs JP, Lebret E, et al. Expert elicitation on ultrafine particles: likelihood of health effects and causal pathways. Part Fibre Toxicol. 2009;6(1):19.

5. BéruBé K, Balharry D, Sexton K, Koshy L, Jones T. Combustion-derived nanoparticles: Mechanisms of pulmonary toxicity. Clin Exp Pharmacol Physiol. 2007;34(10):1044-50.

6. Wang Y, Zhu Y, Salinas R, Ramirez D, Karnae S, John K. Roadside measurements of ultrafine particles at a busy urban intersection. J Air Waste Manage Assoc. 1995. 2008;58(11):1449-57.

7. Sioutas C, Delfino RJ, Singh M. Exposure assessment for atmospheric ultrafine particles (ufps) and implications in epidemiologic research. Environ Health Perspect. 2005;113(8):947-55.

8. Delfino RJ, Staimer N, Tjoa T, Gillen DL, Polidori A, Arhami M, et al. Air pollution exposures and circulating biomarkers of effect in a susceptible population: Clues to potential causal component mixtures and mechanisms. Environ Health Perspect. 2009:117(8):1232-8.

9. Peters A, von Klot S, Heier M, Trentinaglia I, Hörmann A, Wichmann HE, et al. Exposure to traffic and the onset of myocardial infarction. New England J Med. 2004;351(17):1721-30. PMID: 15496621.

10. Leitte AM, Schlink U, Herbarth O, Wiedensohler A, Pan X-C, Hu M, et al. Size-segregated particle number concentrations and respiratory emergency room visits in beijing, china. Environ Health Perspect. 2010;119(4):508-13.

11. Mills NL, Miller MR, Lucking AJ, Beveridge J, Flint L, Boere AJF, et al. Combustion-derived nanoparticulate induces the adverse vascular effects of diesel exhaust inhalation. Eur Heart J. 2011;32(21):2660-71.

12. Whitsel EA, Quibrera PM, Christ SL, Liao D, Prineas RJ, Anderson GL, et al. Heart rate variability, ambient particulate matter air pollution, and glucose homeostasis: the environmental epidemiology of arrhythmogenesis in the women's health initiative. Am J Epidemiol. 2009;169(6):693-703.

13. Park SK, Auchincloss AH, O'Neill MS, Prineas R, Correa JC, Keeler J, et al. Particulate air pollution, metabolic syndrome, and heart rate variability: The multi-ethnic study of atherosclerosis (mesa). Environ Health Perspect. 2010;118(10):1406-11.
14. Schneider A, Neas LM, Graff DW, Herbst MC, Cascio WE, Schmitt MT, et al. Association of cardiac and vascular changes with ambient pm2.5 in diabetic individuals. Part Fibre Toxicol. 2010;7(1):14.

15. Schneider A, Hampel R, Ibald-Mulli A, Zareba W, Schmidt G, Schneide $\mathrm{R}$, et al. Changes in deceleration capacity of heart rate and heart rate variability induced by ambient air pollution in individuals with coronary artery disease. Part Fibre Toxicol. 2010;7(1):29.

16. Zanobetti A, Gold DR, Stone PH, Suh HH, Schwartz J, Coull BA, et al. Reduction in heart rate variability with traffic and air pollution in patients with coronary artery disease. Environ Health Perspect. 2010;118(3):324-30.

17. Hillebrand S, Gast KB, De Mutsert R, Swenne CA, Jukema JW, Middeldorp S, et al. Heart rate variability and first cardiovascular event in populations without known cardiovascular disease: Meta-analysis and dose-response meta-regression. Europace. 2013;15(5):742.

18. Liao D, Carnethon M, Evans GW, Cascio WE, Heiss G. Lower heart rate variability is associated with the development of coronary heart disease in individuals with diabetes. Diabetes. 2002;51(12):3524

19. Adar SD, Gold DR, Coull BA, Schwartz J, Stone PH, Suh H. Focused exposures to airborne traffic particles and heart rate variability in the elderly. Epidemiology. 2007;18(1):95-103.

20. Huang W, Zhu T, Pan X, Hu M, Lu S-E, Lin Y, et al. Air pollution and autonomic and vascular dysfunction in patients with cardiovascular disease: interactions of systemic inflammation, overweight, and gender. Am J Epidemiol. 2012;176(2):117-26.

21. Weichenthal S, Kulka R, Dubeau A, Martin C, Wang D, Dales R. Traffic-related air pollution and acute changes in heart rate variability and respiratory function in urban cyclists. Environ Health Perspect. 2011;119(10):1373-8.

22. Rich DQ, Zareba W, Beckett W, Hopke PK, Oakes D, Frampton MW, et al Are ambient ultrafine, accumulation mode, and fine particles associated with adverse cardiac responses in patients undergoing cardiac rehabilitation? Environ Health Perspect. 2012;120(8):1162-9.

23. Park SK, O'Neill MS, Vokonas PS, Sparrow D, Schwartz J. Effects of air pollution on heart rate variability: the va normative aging study. Environ Health Perspect. 2005;113(3):304-9.

24. Chen J-C, Stone PH, Christiani DC. Obesity is a modifier of autonomic cardiac responses to fine metal particulates. Environ Health Perspect. 2007;115(7):1002-6.

25. Stewart JC, Chalupa DC, Devlin RB, Frasier LM, Huang L-S, Little EL, et al. Vascular effects of ultrafine particles in persons with type 2 diabetes. Environ Health Perspect. 2010;118(12):1692-8.

26. Huang Y-CT, Schmitt M, Yang Z, Que LG, Stewart JC, Frampton MW, et al. Gene expression profile in circulating mononuclear cells after exposure to ultrafine carbon particles. Inhalation Toxicol. 2010;22(10): 835-46. PMID: 20507211

27. Gong J, Zhu T, Kipen H, Wang G, Hu M, Guo Q, et al. Comparisons of ultrafine and fine particles in their associations with biomarkers reflecting physiological pathways. Environ Sci Technol. 2014;48(9):5264.

28. Lucking AJ, Lundbäck M, Barath SL, Mills NL, Sidhu MK, Langrish JP, et al. Particle traps prevent adverse vascular and prothrombotic effects of diesel engine exhaust inhalation in men. Circulation. 2011;123(16):1721-8.

29. Samet JM, Rappold A, Graff D, Cascio WE, Berntsen JH, Huang Y-CT, et al. Concentrated ambient ultrafine particle exposure induces cardiac changes in young healthy volunteers. Am J Respir Crit Care Med. 2009;179(11):1034-42

30. Chan C-C, Chuang K-J, Shiao G-M, Lin L-Y. Personal exposure to submicrometer particles and heart rate variability in human subjects. Environ Health Perspect. 2004;112(10):1063-7.

31. Vora R, Zareba W, Utell MJ, Pietropaoli AP, Chalupa D, Little EL, et al. Inhalation of ultrafine carbon particles alters heart rate and heart rate variability in people with type 2 diabetes. Part Fibre Toxicol. 2014;11(1):31.

32. Esler M, Rumantir M, Wiesner G, Kaye D, Hastings J, Lambert G. Sympathetic nervous system and insulin resistance: from obesity to diabetes. Am J Hypertens. 2001;14(11, Supplement 1):304-9.

33. Straznicky NE, Lambert EA, Lambert GW, Masuo K, Esler MD, Nestel PJ. Effects of dietary weight loss on sympathetic activity and cardiac risk factors associated with the metabolic syndrome. J Clin Endocrinol Metab. 2005;90(11):5998-6005

34. Schroeder EB, Chambless LE, Liao D, Prineas RJ, Evans GW, Rosamond $W D$, et al. Diabetes, glucose, insulin, and heart rate variability: the atherosclerosis risk in communities (aric) study. Diabetes Care. 2005;28(3): 668-74 
35. Liao D, Cai J, Brancati FL, Folsom A, Barnes RW, Tyroler HA, et al. Association of vagal tone with serum insulin, glucose, and diabetes mellitus-the aric study. Diabetes Res Clin Pract. 1995;30(3):211-21.

36. Min J-Y, Paek D, Cho S-I, Min K-B. Exposure to environmental carbon monoxide may have a greater negative effect on cardiac autonomic function in people with metabolic syndrome. Sci Total Environ. 2009:407(17):4807-11.

37. Keaney JF Jr, Larson MG, Vasan RS, Wilson PWF, Lipinska I, Corey D, et al. Obesity and systemic oxidative stress: Clinical correlates of oxidative stress in the framingham study. Arteriosclerosis, Thrombosis, and Vascular Biol: J Am Heart Assoc. 2003;23(3):434-9.

38. Olusi SO. Obesity is an independent risk factor for plasma lipid peroxidation and depletion of erythrocyte cytoprotectic enzymes in humans. Int J Obesity Relat Disorders. 2002;26(9):1159-64.

39. Hotamisligil GS. Inflammation and metabolic disorders. Nature. 2006;444(7121):860-7.

40. Lumeng CN, DeYoung SM, Bodzin JL, Saltiel AR. Increased inflammatory properties of adipose tissue macrophages recruited during diet-induced obesity. Diabetes. 2007;56(1):16-23.

41. Otani H. Oxidative stress as pathogenesis of cardiovascular risk associated with metabolic syndrome. Antioxidants Redox Signaling. 2011;15(7): 1911-26.

42. Sun $Q$, Yue P, Deiuliis JA, Lumeng CN, Kampfrath T, Mikolaj MB, et al. Ambient air pollution exaggerates adipose inflammation and insulin resistance in a mouse model of diet-induced obesity. Circulation. 2009;119(4):538-46.

43. Gold DR. Vulnerability to cardiovascular effects of air pollution in people with diabetes. Curr Diabetes R. 2008;8(5):333-5.

44. Künzli N, Jerrett M, Mack WJ, Beckerman B, LaBree L, Gilliland F, et al. Ambient air pollution and atherosclerosis in los angeles. Environ Health Perspect. 2005;113(2):201-6.

45. Brook RD, Jerrett M, Brook JR, Bard RL, Finkelstein MM. The relationship between diabetes mellitus and traffic-related air pollution. J Occup Environ Med/Am College Occup Environ Med. 2008;50(1):32-8.

46. Krämer U, Herder C, Sugiri D, Strassburger K, Schikowski T, Ranft U, et al. Traffic-related air pollution and incident type 2 diabetes: results from the salia cohort study. Environ Health Perspect. 2010;118(9):1273-9.

47. Puett RC, Hart JE, Schwartz J, Hu FB, Liese AD, Laden F. Are particulate matter exposures associated with risk of type 2 diabetes? Environ Health Perspect. 2010;119(3):384-9.

48. Wang M, Zhu T, Zheng J, Zhang R, Zhang S, Xie X, et al. Use of a mobile laboratory to evaluate changes in on-road air pollutants during the beijing 2008 summer olympics. Atmos Chem Phys. 2009;9(21):8247-63.

\section{Submit your next manuscript to BioMed Central and take full advantage of:}

- Convenient online submission

- Thorough peer review

- No space constraints or color figure charges

- Immediate publication on acceptance

- Inclusion in PubMed, CAS, Scopus and Google Scholar

- Research which is freely available for redistribution 